\title{
Eliciting donations to disaster victims: Psychological considerations
}

\author{
Hanna Zagefka, ${ }^{1}$ Masi Noor, ${ }^{2}$ Rupert Brown, ${ }^{3}$ Tim Hopthrow ${ }^{4}$ and \\ Georgina Randsley de Moura ${ }^{4}$ \\ ${ }^{1}$ Royal Holloway University of London, Egham, UK, ${ }^{2}$ Canterbury Christ Church University, Canterbury, UK, \\ ${ }^{3}$ University of Sussex, Falmer, UK, and ${ }^{4}$ University of Kent, Canterbury, UK
}

\begin{abstract}
Predictors of monetary donations to victims of humanitarian disasters were examined. Participants $(N=219)$ chose between donating to different scenarios and justified their choices in an open response format. This was followed by a questionnaire. The perceived extent of the victims' Need, the Impact of a potential donation, and the Amount donated by others all influenced donation decisions. There was a three-way interaction between these factors: The perceived Need for help only mattered if the perceived Impact of a donation was high, and the perceived Amount donated by others was small. Implications for theory and practice are discussed.
\end{abstract}

Key words: donations, helping, pro-social behaviour.

Many people donate to disaster relief appeals (Wrathall \& Ellis, 2006). Such appeals are so plentiful that donors have a number of different causes to choose from at any given moment in time. An intriguing question is how donors decide which cause to choose. There are large variations in donations following real-life disasters [see, e.g., the United Nations Office for the Coordination of Humanitarian Affairs (UN's OCHA), http://ochaonline. un.org/]. For example, individual giving after the Asian Tsunami of 2004 was impressive, but other equally worthy causes, such as the large-scale humanitarian crisis in Darfur, were less popular (Baker, 2005). The aim of the present research was to study the factors that lead individuals to decide to donate to a certain cause, and through this - to explain why some relief appeals are so much more successful than others.

Prior (psychological and non-psychological) work on predictors of monetary donations has focused on a range of factors (e.g., Garcia, Weaver, Moskowitz, \& Darley, 2002; Holmes, Miller, \& Lerner, 2002; Jonas, Schimel, Greenberg, \& Pyszczynski, 2002; Knight, Johnson, Carlo, \& Eisenberg, 1994; Levy, Freitas, \& Salovey, 2002; Levy, West, Ramirez, \& Karafantis, 2006). For example, perceptions of individual charities have been analysed, explaining why people donate to one organization rather than another (Sargeant \& Lee, 2004). Different advertising methods have been studied, such as the use or omission of pictures (Perrine \& Heather, 2000; Strack, Schwarz, \& Kronen-

Correspondence: Hanna Zagefka, Department of Psychology, Royal Holloway University of London, Egham, TW20 0EX, UK. Email hanna.zagefka@rhul.ac.uk

This work was supported by an Economic and Social Research Council grant awarded to the first author, RES-000-22-1817.

Received 28 July 2011; accepted 13 February 2012. berger, 1987). The effects of individual difference variables have been highlighted, such as demographic and financial characteristics of the donor (Wunderink, 2002). Situational variables such as mortality salience have also been investigated (Ferraro, Shiv, \& Bettman, 2005). Factors predicting donations have been found to be diverse, ranging from media coverage (Simon, 1997) to empathy (Warren \& Walker, 1991), victim blame (Campbell, Carr, \& MacLachlan, 2001; Cheung \& Chan, 2000), identifiability of the victim (Kogut \& Ritov, 2011; see also Slovic, 2007), and emotional factors such as guilt (Basil, Ridgway, \& Basil, 2008; Hibbert, Smith, Davies, \& Ireland, 2007), to name but a few.

Factors which have been found to influence pro-social behaviour other than donations (e.g., Batson, 1998; Deaux, Dane, \& Wrightsman, 1993; Dovidio, Piliavin, Schroeder, \& Penner, 2006; Penner, Dovidio, \& Piliavin, 2005; Saucier, Miller, \& Doucet, 2005; Simmons, 1991) have often highlighted similar antecedents; for example, empathy (Batson, 1998), victim blame (Betancourt, 1990), and intergroup variables (Levine, Cassidy, Brazier, \& Reicher, 2002; van Leeuwen, 2007).

Although much psychological work has been done to identify predictors of pro-social behaviour in general, and some psychological work exists specifically predicting donations, few studies have examined donations to disaster victims. This type of helping is unique in that it involves large groups in great need. One aim of the present contribution was to advance our theoretical understanding of pro-social behaviour by focusing on this hitherto neglected type of helping.

Another important aim was to highlight the importance of considering the interplay between different antecedents of helping. Very few contributions have studied how different predictors of donations or pro-social behaviour more generally might interact with each other. This is a vital issue, given 
that moderating effects can often plausibly be proposed. What is more, if the effectiveness of one predictor in triggering donations might depend on the presence or absence of a second or third factor, this could have important practical and policy implications which should be considered when designing campaigns to elicit donations.

In the present contribution, we explore the interplay between three potential predictors of donations, namely the perceived extent of the victims' Need, the Impact of a potential donation, and the Amount donated by others. None of these factors have received as much research attention as, for instance, empathy or victim blame (but, see Atkinson, 2009, for some interesting insights). Because one can make contradictory predictions about the potential effects of Amount, it is particularly interesting to study this variable, and to investigate how it might interact with other factors such as perceived Need and Impact.

\section{Perceived need for help}

It has been shown that the severity of a given disaster impacts on people's donation decisions (Levine \& Thompson, 2004; Simon, 1997). This is presumably because perceived severity influences the perceived extent of the need for help. Indeed, the perceived extent of need has been found to be an important determinant of pro-social acts in a range of different settings (Batson, 1998; Batson, Lishner, Cook, \& Sawyer, 2005; Batson et al., 1997; Cheung \& Chan, 2000; Cialdini, Brown, Lewis, \& Neuberg, 1997; Holmes et al., 2002; Staub, 1974; Stroebe \& Stroebe, 1996). Of course, it is sensible to offer help only where it is needed. In the present context, we expected that a higher perceived need for help would lead to a greater willingness to donate.

\section{Perceived impact of a potential donation}

Previous research has shown that in order to donate to a certain organization, people need to be confident that the organization will spend their money wisely (Polonsky, Shelley, \& Voola, 2002; Sargeant \& Lee, 2004). We propose that it is not only trust in organizations that matters, but also trust that a donation will make a difference in the field. After all, the most ethical and competent organization might not be able to assure that money is well spent if they are forced to cooperate with corrupt politicians, or if the disaster situation is very chaotic and complicated. Considering these factors, a potential donor can arrive at an assessment of the likely impact his/her donation might have. Indeed, research showing that the proportion of lives saved by an intervention motivates people more strongly than the total amount of lives saved is indicative of the fact that people are concerned with the impact their donation will have (Fetherstonhaugh, Slovic, Johnson, \& Friedrich,
1997). Therefore, one would expect that people will only donate if they expect that their money will make a difference and actually reach those in need (see also Cheung \& Chan, 2000; Warren \& Walker, 1991). Hence, we expect that a higher perceived impact of a potential donation would be associated with a greater willingness to donate.

\section{Perceived amount donated by others}

Another factor likely to influence decisions of whether to donate is the perceived amount donated by others. Work on the bystander effect has shown that the presence of others can lead to a diffusion of responsibility, so that people fail to help because they assume others should/will do so (Darley \& Latane, 1968; Garcia et al., 2002; Latane \& Nida, 1981). One study which tested the bystander effect in the context of donations showed that solitary participants were more likely to make a charitable donation than those who were in a group (Wiesenthal, Austrom, \& Silverman, 1983; see also Radley \& Kennedy, 1995). Hence, we hypothesize that if people assume that others will donate money, they are less inclined to donate themselves.

It should be noted that on the basis of work showing the positive effect of role models on helping, one could also predict a positive effect of donations by others on one's own willingness to donate (see, e.g., Basil, Ridgway, \& Basil, 2006; Krebs, 1970; Rushton, 1975; also Frey \& Meier, 2004). The same prediction could be made on the grounds of normative influence theory (Cialdini, Reno, \& Kallgren, 1990), and the effect seems to be particularly strong if the others in question are in-group members (Levine et al., 2002). However, in situations where a finite amount of help is needed, it seems more likely that help offered by others leads to a diffusion of responsibility, along the lines of the bystander effect. Hence, we expect a negative effect of donations by others on willingness to donate in the present context.

\section{Proposed interaction}

One might not only expect each of the three factors - Need, Impact, and Amount donated by others - to directly affect willingness to donate, but one might also expect an interaction between them. Particularly, Need should only be important if the perceived Impact is not too low and if the Amount donated by others is not too high. If someone believes that his/her money has no chance of reaching the right people, and if someone believes that others have already taken on the responsibility of rectifying the situation, it might make little sense for this person to donate, no matter how high the original need of the victims. In other words, if the potential help is ineffectual, and if others are 
already helping anyway, perceiving someone to be needy should not lead to helping.

\section{Natural versus humanly caused events}

Of course, given the huge array of variables that have been shown to impact on helping, we did not mean to suggest that Need, Impact, and Amount donated by others would be the only influential factors. Although these were our main focus, we were also interested to explore the effects of other factors, in particular the perceived cause of the event, that is, whether it was perceived to be naturally occurring or humanly caused. In some previous research we found that people seem to be more willing to donate to victims of naturally caused events because they tend to be blamed less for their plight, and they tend to be perceived as making more of an effort to help themselves (Zagefka, Noor, Brown, Randsley de Moura, \& Hopthrow, 2011). The effects of these factors are therefore explored here too.

In sum, it is hypothesized that a high perceived Need for help and a high perceived potential Impact of a donation would have positive effects on willingness to donate, and that a high perceived Amount donated by others would have a negative effect. It is further proposed that these three factors might interact in their effects on willingness to donate, such that Need would not be effective if the perceived Impact of a potential donation is low and if the perceived Amount donated by others is high. The effects of other factors on willingness to donate are also explored, with particular interest in the effect of the perceived cause of the disaster.

These hypotheses were tested in a study which consisted of two parts, one where participants responded to several real-life disasters using an open-end response format, and a second part where participants' responses regarding one particular real-life disaster were assessed with Likertscales in a questionnaire. The first part was designed to be open-ended and qualitative, and the second part quantitative. These two elements were combined because each one offers unique advantages: the open-ended response format is ideally placed to unearth which concerns people have intrinsically when contemplating where to donate. It would be much harder to tap into such unadulterated factors with an experimental design, which already incorporates some $a$ priori assumptions on the part of the researcher which might influence the participants' responses. In contrast, the quantitative design (and its experimental element) is the method of choice when the goal is to study causal relationships; and this is clearly the case for a study of the predictors of donations. A quantitative methodology is also better placed for studying complicated interactions between factors which might drive donation decisions even without donors necessarily having insight into them, or being able to report them. The open-ended part sought to confirm that
Need, Impact and Amount feature prominently in people's freely generated rationales for donating. The quantitative part sought to confirm that these three factors impact on donations using a different methodology, and to study the interplay and possible interaction between the three factors.

Although no part of the world is safe from humanitarian crisis, recently Asia has experienced more than its fair share of natural and humanly-caused disasters (e.g., the 2004 Tsunami, the Nepali Civil War, the Sri Lankan Conflict, the Fukushima Nuclear Disaster, etc.). Moreover, while there is a growing body of work shedding insights into how Asian victims cope with these disasters, little or no work has examined how the Asian disaster victims are perceived by potential Western aid donors and what social psychological factors inform such perceptions. To this end, both parts of the present study includes responses to disasters which happened in Asia. Thus, the study of predictors of donations is of particular interest to Asian social psychology and beyond.

\section{Method}

\section{Participants}

Two hundred and nineteen British students participated in the study in exchange for course credits. The mean age was 20.32 years. There were 38 male and 181 female participants.

\section{Design}

The study consisted of two parts. Part one had an openended response format asking about seven different reallife disaster events (these were presented within participants, i.e., each participant responded to all seven), and part two consisted of a questionnaire. There were two versions of the questionnaire, one asking about the Tsunami disaster in Asia in 2004, and one asking about the Darfur disaster in Sudan (this was a between participants factor). Participants were randomly assigned to either the Tsunami $(N=111)$ or the Darfur $(N=108)$ condition. Hence, disaster type was a between participants factor with two levels. The disaster was varied between participants in the second part of the study to get confirmation that the pattern of results would generalize across different events and that they are therefore not event specific. A further aim was to obtain some further tentative evidence that people are more comfortable donating to disasters with natural causes (Tsunami) than human causes (Darfur). We consider this second aspect 'tentative' because the two events differ on a whole range of factors, making firm conclusions difficult. Data were collected in 2005, at a time when both events were still well covered in the media. 


\section{Procedure and measures - open-ended part}

Participants were presented with seven real-life topical disaster scenarios. Disasters were chosen so that there were two events for each of the main regions: Asia, Africa, and Central America. Only one disaster event was included for North America, because at the time the study was conducted, no other event had occurred that would have been sufficiently high-profile in order for the participants to have heard about it.

A short description of each disaster was given. In order not to introduce unnecessary confounds, the descriptions were standardized as much as possible. For example, participants read that 'thousands of people have died ...', rather than being given more concrete information. Of course, some differences in the descriptions could not be avoided, given the very different nature of these real-life disasters. The concrete wording is given in Appendix I. The order in which participants read about the seven disasters was randomized via Latin square method. The following disasters were included:

civil war in Colombia (Central America); famine in West Africa (Africa); earthquake in Pakistan, India, and Kashmir (Asia); civil war in Sudan (Africa); Hurricane Stan victims in Guatemala and other Central American countries (Central America); civil war in Nepal (Asia); and Hurricane Katrina in the USA (North America).

After reading these scenarios, participants were asked to imagine that they had $£ 10$ to donate, and that they would be able to give either all $£ 10$ to just one cause, or $£ 5$ each to two of the causes. They then indicated where they would donate their money. The options given to participants were meant to reflect the fact that in real life too people can choose to put 'all their eggs in one basket' or to 'spread the goodness'. For each disaster, participants were also asked to write down up to three reasons why they either would choose or not choose to donate to it. Participants then moved on to the questionnaire survey.

\section{Procedure and measures - questionnaire survey}

In the Tsunami condition, items were preceded by the following text: 'Thousands of people died when the big tidal wave hit the coast of several Asian countries last year, and many more had their livelihoods destroyed. They depended on outside help to survive and rebuild their lives'. In the Darfur condition, items were preceded by the following text: 'Thousands of people died in Sudan's province of Darfur at the hand of a rival ethnic group, and many more had to flee to save their lives. Those refugees were dependent on outside help to survive and rebuild their lives'. This was followed by the following scales.
Need for help. Participants' perceptions about the need for help were assessed by two items $(1=$ disagree strongly to 7 = agree strongly): 'I believe that there was a huge need for outside help after the [Tsunami/Darfur] disaster'; and 'I believe that huge amounts of money and funds were needed after the disaster to help survivors'; $r=0.86$.

Impact of donation. Participants' perceptions about the likely impact of a donation were assessed using five items $(1=$ disagree strongly to $7=$ agree strongly): 'I believe that money donated to the [Tsunami/Darfur] victims had a fair chance of making a real difference and of improving things'; 'I believe the money donated to the victims was likely to be well-spent'; 'I believe that the money donated to the victims was likely to reach those most in need'; 'I believe that money donated to the victims most likely didn't reach the victims, but just benefited corrupt politicians and fanatics in power positions' (reverse scored); and 'I believe that money donated to the victims was just money down the drain, because it would not have reached those who really need it' (reverse scored); $\alpha=0.89$.

Amount donated by others. Participants' beliefs about how much others had donated were assessed with two items $(1=$ disagree strongly to $7=$ agree strongly): 'I believe that so many other people have or will still donate to the victims that my own money will not be required'; and 'I believe that so many other people have or will still donate to the victims that my own help is unnecessary'; $r=0.85$.

Willingness to donate. A five-item scale measured participants' willingness to donate money to the victims of the disaster $(1=$ not at all to $7=$ very much $)$ : 'I would be willing to give donations to the victims of the disaster'; 'I think it is important to give donations to the victims'; 'I think it is the right thing to do to give donations to the victims'; 'I think everyone should donate money to the victims'; and 'I would give the maximum amount I could afford to the victims'; $\alpha=0.82$.

The questionnaire also included some questions about demographic information and some items which are not of relevance in the present context. Upon completion of the study, participants were thanked and debriefed.

\section{Results}

\section{Open-ended part: Reasons given for donating/not donating}

For each disaster, the frequency of people fictitiously donating money was calculated. The results are displayed in Table 1. As can be seen, no particular continent seems to have been favoured by participants. However, what can be 
Table 1 Donations to different disasters

\begin{tabular}{lllcrl}
\hline & Continent & Cause & $\begin{array}{c}\text { Times £5 were } \\
\text { donated }\end{array}$ & $\begin{array}{c}\text { Times £10 } \\
\text { were donated }\end{array}$ & $\begin{array}{c}\text { Total times a } \\
\text { donation was made } \\
\text { donated }\end{array}$ \\
\hline West Africa & Africa & Natural & 125 & 29 & 154 \\
Pakistan & Asia & Natural & 82 & 13 & 95 \\
Katrina & North America & Natural & 29 & 3 & 32 \\
Stan & South America & Natural & 22 & 3 & 25 \\
Sudan & Africa & Human & 27 & 0 & 175 \\
Nepal & Asia & Human & 13 & 5 & 140 \\
Colombia & South America & Human & 16 & 1 & 13 \\
\hline
\end{tabular}

noted is that the four disasters caused by 'natural' factors (poor rainfall, earthquake, hurricane) generated more donations than the three 'humanly-caused' events (civil war). While the average total amount donated to the four natural disasters (West Africa, Pakistan, Katrina, Stan) was $£ 442.50$, the average amount donated to the three humanlycaused disasters (Sudan, Nepal, Colombia) was only $£ 113.33$ (see also Zagefka et al., 2011, for the effect of disaster cause on donations).

A coder read all the statements in which participants explained their donation choices, and identified a list of themes present in them. Semantically similar statements were grouped together into thematic categories. Whenever a statement came up which did not fit into the already identified themes, a new theme was added. Thirteen thematic rationales for donating/not donating were identified in total.

Having compiled this list of 13 themes, the coder went through all the statements again and identified for each statement whether each of the themes was present. A second, independent coder rated the statements in the same way. Across all the statements, there were 2566 instances where the two raters agreed that a rationale was present, and four instances where they disagreed, yielding a total agreement rate of $99 \%$. In the four cases where coders disagreed, discrepancies were discussed until a consensus was reached. The frequency with which each rationale was cited is displayed in Table 2.

Need. Participants cited the need generated by the disaster as a reason for donating/not donating. Sometimes this was done without further specification, e.g. participants just said 'they need a lot of help', or 'the need is not that big compared to other disasters'. However, sometimes further specifications followed. Particularly, the 'victims'finances', the 'scale' of the disaster, and the 'nature' of the disaster were cited. Typical statements that cite the victims' finances are 'it's a poor country, so they need a lot of outside help', or 'the country is quite rich, so they can sort it out themselves'. Typical statements that cited the scale of the disaster are 'lots of nations affected, so lots of help is needed', or
Table 2 Rationales given for donating/not donating

\begin{tabular}{lc}
\hline & Times cited total \\
\hline Need - & \\
Victims' finances & 378 \\
Scale & 228 \\
Unspecified & 199 \\
Nature & 177 \\
TOTAL & 982 \\
Impact & 280 \\
Donations by others & 277 \\
Cause & 270 \\
Victim blame & 161 \\
Media coverage & 159 \\
Knowing/relating to victims & 149 \\
Knowledge of the situation & 131 \\
Personal finances & 106 \\
Political relations & 23 \\
Self help & 21 \\
Counterfactual thought & 6 \\
Political obligation & 5 \\
\hline
\end{tabular}

'there weren't as many victims as for some of the other disasters, so my help is needed more elsewhere'. Typical statements citing the nature of the disaster are "my help is needed here because this is a matter of life and death through starvation, rather than just material problems', or 'they still have their homes; other victims who are starving are more in need'.

Impact of donation. Participants also named the impact a potential donation would have in terms of improving things, for example, 'even a small amount of money would make a big difference to the victims', or 'my money wouldn't make a difference, it's like pouring money down the drain'.

Donations by others. Participants also cited the amount that had been donated by others: 'I'll donate to them because they have had hardly any support so far', or 'this cause has received lots of support already'.

(C) 2012 The Authors Asian Journal of Social Psychology ( 2012 Wiley Publishing Asia Pty Ltd with the Asian Association of Social Psychology and the Japanese Group Dynamics Association 
Other reasons cited were the cause of disaster (e.g., 'I feel less good about giving to man-made disasters'); victim blame (e.g., 'the weather's outside people's control, so they are clearly blameless' or 'it's self-caused'); the media (e.g., 'the media has highlighted it' or 'I didn't hear about it on the news'); and knowing the victims/relating to the victims (e.g., 'I have travelled to Asia so feel an affinity to the people there' or 'I don't understand the way Pakistanis think, so am not motivated to help'). It is noteworthy that 'victim blame' was also often related to the 'cause' of war (e.g., 'it is their own fault that they are at war'; for the link between disaster cause and victim blame, see also Zagefka et al., 2011).

Further rationales given were a lack of knowledge about the situation (e.g., 'I know little about this disaster'); personal finances (e.g., 'I cannot donate to all causes'); political relations (e.g., 'I disagree with the politics of the victim country'); perceived self-help (e.g., 'they should try to help themselves first'); counterfactual thought (e.g., 'if it happened to them it could happen to us'); and political obligation (e.g., 'the country is a former British colony, so Brits should help').

As is apparent from Table 2, and supporting the hypothesis, the most frequently cited reasons for donating/not donating were the severity of the victims' Need, the perceived Impact any donation would have, and the Amount donated by others. This validates the hypothesis that Need, Impact and Amount are important factors in people's decisions about where to donate.

\section{Survey part: Effect of Need, Impact, and Amount on willingness to donate}

The survey part tested in a more quantitative way whether willingness to donate is influenced by the perceived Need for help, the perceived Impact of a potential donation, and the Amount donated by others. It also allowed us to examine potential interactions between these three factors. Bi-variate correlations between the variables are displayed in Table 3.

To begin with, we regressed willingness to donate on Need, Impact, and Amount. To test whether similar patterns would emerge in the Tsunami and the Darfur condition, disaster type (Tsunami vs Darfur) was also entered as a predictor, and the interactions of each of the other three variables with disaster type were entered in a second step in the regression. Both Need and Amount interacted significantly with disaster type, $\beta=-0.53, p<0.05$ and $\beta=0.37$, $p<0.05$, respectively. Consequently, the regression analysis was repeated separately for the Tsunami and the Darfur conditions.

For the Tsunami group, when predicting willingness to donate from Need, Impact and Amount, the overall regression was significant, $R^{2}=0.42 ; \quad F(3,106)=25.86$,
Table 3 Bi-variate correlations, means and standard deviations

\begin{tabular}{|c|c|c|c|c|}
\hline & Need & Impact & $\begin{array}{l}\text { Amount } \\
\text { donated } \\
\text { by others }\end{array}$ & $\begin{array}{l}\text { Willingness } \\
\text { to donate }\end{array}$ \\
\hline Need & & $0.43 * * *$ & -0.11 & $0.45 * * *$ \\
\hline Impact & & & -0.001 & $0.45 * * *$ \\
\hline $\begin{array}{l}\text { Amount } \\
\text { donated } \\
\text { by others }\end{array}$ & & & & $-0.29 * * *$ \\
\hline Means & $5.89(0.99)$ & $4.49(1.34)$ & $2.69(1.33)$ & 4.94 (1.09) \\
\hline
\end{tabular}

$* * * p<0.001 . S D \mathrm{~s}$ in parentheses.

$p<0.001$. The betas were $\beta=0.37, p<0.001$ for Need; $\beta=0.16, p<0.05$ for Impact; and $\beta=-0.35, p<0.001$ for Amount. For the Darfur group, the overall regression was significant, $R^{2}=0.25 ; F(3,104)=11.41, p<0.001$. The betas were $\beta=0.18, p<0.05$ for Need; $\beta=0.38, p<0.001$ for Impact; and $\beta=-0.16, p<0.07$ for Amount.

Results in both conditions supported the hypothesis. The perceived extent of Need and the perceived Impact of a potential donation had positive associations with willingness to donate, while the Amount donated by others had a negative association. In spite of this converging pattern, Impact was a slightly more powerful predictor in the Darfur condition, and Need and Amount were somewhat more powerful predictors in the Tsunami condition. Nonetheless, even though the magnitude of the beta coefficients varied slightly, crucially their overall direction was the same (Need and Impact were positively associated with donations in both scenarios, and Amount was negatively associated with donations in both scenarios). Therefore, in a next step the sample was analysed as a whole, summarising across the two conditions.

A hierarchical regression analysis was performed, predicting willingness to donate from Need, Impact, and Amount (entered as centred predictors in a first step), the three two-way interactions (entered as predictors in a second step), and the three-way interaction (entered in a third step). Including the interaction terms allowed testing the proposition that the three factors would interact in their effects on willingness to donate. The first step of the regression was significant, $F(3,214)=38.69, p<0.001$, and explained $35 \%$ of the variance in willingness to donate. The betas were $\beta=0.27, p<0.001$ for Need; $\beta=0.33$, $p<0.001$ for Impact; and $\beta=-0.26, p<0.001$ for Amount. None of the two-way interactions were significant. However, the three-way interaction was significant, $\Delta R^{2}=0.02, \beta=0.14, p<0.05$.

To interpret the three-way interaction, all three independent variables were median split and entered as predictors into an ANOVA with willingness to donate as a dependent 
Table 4 Effects of Need, Impact, and Amount on willingness to donate: The interaction

\begin{tabular}{ccccc}
\hline & \multicolumn{4}{c}{ Perceived impact } \\
\cline { 2 - 5 } & \multicolumn{3}{c}{ High } & \multicolumn{3}{c}{ Low } \\
\cline { 2 - 5 } & \multicolumn{4}{c}{ Amount donated by others } \\
\cline { 2 - 5 } & high & low & high & low \\
\hline Perceived & $5.28 \mathrm{a}$ & $5.84 \mathrm{a}$ & $4.48 \mathrm{a}$ & $5.38 \mathrm{a}$ \\
Need high & $(1.03)$ & $(0.95)$ & $(1.65)$ & $(0.94)$ \\
Perceived & $4.70 \mathrm{~b}$ & $5.29 \mathrm{~b}$ & $4.35 \mathrm{a}$ & $4.36 \mathrm{~b}$ \\
Need low & $(0.67)$ & $(0.94)$ & $(0.82)$ & $(1.04)$ \\
\hline
\end{tabular}

Values not sharing the same subscripts denote significant differences at $p<0.05$ (column-wise). SDs in parentheses.

variable. Crucially, we were interested in the pairwise comparisons of those low and high in perceived Need in each level combination of the two other factors. As can be seen in Table 4, and as expected, three of the pairwise comparisons were significant, but there was no significant difference for the cell Impact low/Amount donated by others high. Need was only impactful if participants did not feel that their help would be simultaneously ineffective (Impact low) and unnecessary (Amount donated). ${ }^{1}$

An additional analysis was performed to explore whether there would be a mean level difference on willingness to donate between the Tsunami and the Darfur scenario, replicating the pattern of actual donations in the field. Mean level differences between the two scenarios were also tested for the variables Need, Impact, and Amount donated by others. It was expected that willingness to donate would be higher for the disaster with a natural (rather than manmade) cause, and - given the hypothesized relationship between the variables - that the disaster which would attract more willingness to donate would also be the one which is higher on Need and Impact, and lower on Amount.

A MANOVA was conducted with disaster type as the independent variable with two levels (Tsunami vs Darfur) and Need, Impact, Amount donated by others, and willingness to Donate as dependent variables. The multivariate effect was significant, $F(4,213)=26.81, p<0.001$. Means and univariate $F \mathrm{~s}$ are displayed in Table 5. As is apparent, all differences were significant (apart from the one for Amount - this was only marginally significant) and the patterns of means were in the expected direction - that disaster which attracted more willingness to donate was also the one with higher perceived Need and Impact, and lower Amount.

\section{Discussion}

Both the open-ended response part and the survey part of the study yielded clear evidence that people are more
Table 5 Mean level differences between the two disaster scenarios

\begin{tabular}{lcccc}
\hline & & & \multicolumn{1}{c}{$\begin{array}{c}\text { Amount } \\
\text { donated } \\
\text { by others }\end{array}$} & \multicolumn{1}{c}{$\begin{array}{c}\text { Willingness } \\
\text { to donate }\end{array}$} \\
\hline Tsunami & $6.33(0.73)$ & $5.12(1.07)$ & $2.86(1.42)$ & $5.20(1.07)$ \\
Darfur & $5.42(1.00)$ & $3.84(1.28)$ & $2.52(1.21)$ & $4.66(1.04)$ \\
$F$ & $58.18 * * *$ & $64.09 * * *$ & $3.52 \bullet$ & $13.91 * * *$ \\
\hline
\end{tabular}

$* * * p<0.001 ; \bullet p<0.07 . S D$ s in parentheses.

willing to donate if they think that the need for donations is high, if they think the donation is likely to have a substantial impact, and if they think that donations by others are comparatively low. The survey data also yielded evidence that the three factors interacted in the predicted way. The perceived need for help only impacted on willingness to donate if the perceived impact of a potential donation was high and the perceived amount donated by others was low. This demonstrates that it is important to consider the interplay between different antecedents of pro-social behaviour, rather than to consider them singly. The moderation we found has important practical implications, as will be elaborated below.

The fact that Impact was a slightly more powerful predictor in the Darfur case and Need and Amount donated by others were slightly more powerful in the Tsunami case might be due to media effects. These might have made participants more sensitive to impact issues for Darfur (e.g., because of the media highlighting the issue of a corrupt government in Sudan) and to need issues and issues arising by donations by others for the Tsunami. However, importantly, Need and Impact were positively associated with willingness to donate for both disasters, and the Amount donated by others was negatively associated with willingness to donate for both disasters.

\section{Limitations and strengths}

One limitation of the present study is that only self-reported willingness to donate rather than actual donations were measured. Although it would have been nice to be able to measure actual donations if this had been practically feasible, there is evidence that self-reports correlate very highly with what people would actually donate (Zagefka et al., 2011). Hence, although some level of caution is indicated, we would argue that self-reports can be interpreted as an economical way of measuring behavioural tendencies and as a strong predictor of actual behaviour.

Another important feature of this work was that it focused on real-life disasters. Therefore, it cannot be ruled out with certainty that the mean-level differences between 
the Tsunami and Darfur events found in the survey part of the study might have been caused by confounds. Future research could usefully investigate the hypothesiszd effects, but using fictitious disasters, hence allowing a better level of control over extraneous variables. Then again, choosing real-life disasters furnishes better confidence about the ecological validity of results. Given that one main aim of this work was to provide insights of applied importance, this was deemed especially valuable.

\section{Implications for theory}

One aim of this research was to advance our theoretical understanding of pro-social behaviour, by extending the research from types of helping traditionally studied to a novel type of helping, namely help for large groups in great need. This type of help has, to date, received little attention from psychologists, and we know little about what causes people to treat different victim groups differently. The present research aims to make some headway in this respect. Another important aim was to highlight the importance of considering the interplay between different antecedents of donations. Such moderation effects are also likely to exist for types of pro-social behaviour other than donations, and future research could investigate such effects in other pro-social settings.

\section{Implications for practice}

In designing disaster relief appeals, it will be beneficial to explicitly include information about the severity of the victims' Need, the Impact a potential donation could have, and the Amount already donated by others. The importance of not considering one factor singly but considering the interplay between different factors when eliciting donations has also been demonstrated when focusing on predictors of donations other than the ones highlighted here (e.g., Chang, 2008). It will be important to include information on all three factors highlighted, given that the interaction demonstrated that Need will have virtually no effect if optimal conditions are not present with regard to the perceived Impact and Amount donated by others. This suggests that the many relief appeals which particularly stress the Need for help (by emphasizing the scale of the disaster, the number of people in need, the amount of funds required, etc.) might not be effective at eliciting donations if people's preconceived ideas regarding Impact and Amount are not ideal, that is, if people believe their money will not make a difference, and if people believe that others already have or will step up to help. For a more effective strategy, one would need to stir people's ideas about all three factors simultaneously, by providing information on Need, Impact, and Amount. In other words, relief appeals must address all three factors simultaneously; they should not only emphasize that many donations are needed, but also that donations are likely to reach and make a real difference to the victims, and that the public has not been very responsive so far. Considering these factors in appeal design might well significantly increase donations.

We would, however, like to conclude with a cautionary note. Although the present data suggest that Need, Impact and Amount are important, they will not be the only important factors. Indeed, people often offer rational explanations for their behaviour (such as the perceived Need or Impact as a driver of donation decisions) even if this behaviour is actually driven by non-rational factors (Haidt, 2001). Further, perceptions of Need or Impact might themselves not be based in reality but driven by psychological factors such ideology, donor personality (Bennett, 2003), selfexpression needs (Moore, 2008), or wishful thinking (Kelley, 1989). Moreover, different types of emotions drive different kinds of helping (Thomas, McGarty, \& Mavor, 2009). To date we know nothing about how messages about Need, Impact and Amount affect and are affected by such emotions. More research on both non-rational drivers of donations and different emotional mediators would be needed before firm conclusions can be drawn about the best strategy to elicit donations. The present contribution should be seen as a starting point, rather than as presenting the final conclusion on the matter.

\section{Endnote}

1. A similar pattern of results was obtained when using simple slopes analysis to interpret the interaction.

\section{References}

Atkinson, A. B. (2009). Giving overseas and
public policy. Journal of Public Economics,
93, 647-653.
Baker, D. (2005). Not a swell time for
charities. Individual giving for the tsunami was impressive, but other causes are suffering as a result. Financial Times, 19 Feb.

Basil, D. Z., Ridgway, N. M. \& Basil, M. D. (2006). Guilt appeals: The mediating effect of responsibility. Psychology and Marketing, 23, 1035-1054
Basil, D. Z., Ridgway, N. M. \& Basil, M. D. (2008). Guilt and giving: A process model of empathy and efficacy. Psychology and Marketing, 25, 1-23.

Batson, C. D. (1998). Altruism and prosocial behavior. In: D. T. Gilbert, S. T. Fiske \& G. Lindzey, eds. The Handbook of

(C) 2012 The Authors

Asian Journal of Social Psychology ( 2012 Wiley Publishing Asia Pty Ltd with the Asian Association of Social Psychology and the Japanese Group Dynamics Association 
SocialPsychology, Vol. II. pp. 282-316. New York: McGraw-Hill.

Batson, C. D., Lishner, D. A., Cook, J. \& Sawyer, S. (2005). Similarity and nurturance: Two possible sources of empathy for strangers. Basic and Applied Social Psychology, 27, 15-25.

Batson, C. D., Sager, K., Garst, E., Kang, M., Rubchinsky, K. \& Dawson, K. (1997). Is empathy-induced helping due to self-other merging? Journal of Personality and Social Psychology, 73, 495-509.

Bennett, R. (2003). Factors underlying the inclination to donate to particular types of charity. International Journal of Nonprofit and Voluntary Sector Marketing, 8, 12-29.

Betancourt, H. (1990). An attribution-empathy model of helping behavior: Behavioral intentions and judgments of help-giving. Personality and Social Psychology Bulletin, 16, 573-591.

Campbell, D., Carr, S. C. \& MacLachlan, M. (2001). Attributing 'third world poverty' in Australia and Malawi: A case of donor bias? Journal of Applied Social Psychology, 31, 409-430.

Chang, C.-T. (2008). To donate or not to donate? Product characteristics and framing effects of cause-related marketing on consumer purchase behaviour. Psychology and Marketing, 25, 1089-1110.

Cheung, C. K. \& Chan, C. M. (2000). Socialcognitive factors of donating money to charity, with special attention to an international relief organization. Evaluation and Program Planning, 23, 241-253.

Cialdini, R. B., Brown, S. L., Lewis, C. L. \& Neuberg, S. L. (1997). Reinterpreting the Empathy-Altruism Relationship: When one into one equals oneness. Journal of Personality and Social Psychology, 73, 481-494.

Cialdini, R. B., Reno, R. R. \& Kallgren, C. A. (1990). A focus theory of normative conduct: Recycling the concept of norms to reduce littering in public places. Journal of Personality and Social Psychology, 58, 1015-1026.

Darley, J. M. \& Latane, B. (1968). Bystander intervention in emergencies: Diffusion of responsibility. Journal of Personality and Social Psychology, 8, 377-383.

Deaux, K., Dane, F. C. \& Wrightsman, L. S. (1993). Prosocial behaviour (Chapter 11). In: K. Deaux, F. C. Dane \& L. S. Wrightsman, eds. Social Psychology in the '90s, pp. 286-311. Pacific Groove: Pacific Gove Brooks/Cole.
Dovidio, J. F., Piliavin, J. A., Schroeder, D. A. \& Penner, L. (2006). The Social Psychology of Prosocial Behavior. Mahwah, NJ: Lawrence Erlbaum.

Ferraro, R., Shiv, B. \& Bettman, J. R. (2005) Let us eat and drink, for tomorrow we shall die: Effects of mortality salience and selfesteem on self-regulation in consumer choice. Journal of Consumer Research, 32, 65-75.

Fetherstonhaugh, D., Slovic, P., Johnson, S. M. \& Friedrich, J. (1997). Insensitivity to the value of human life: A study of psychophysical numbing. Journal of Risk and Uncertainty, 14, 283-300.

Frey, B. S. \& Meier, S. (2004). Pro-social behavior in a natural setting. Journal of Economic Behavior \& Organization, 54, 65-88.

Garcia, S. M., Weaver, K., Moskowitz, G. B. \& Darley, J. M. (2002). Crowded minds: The implicit bystander effect. Journal of Personality and Social Psychology, 83, 843-853.

Haidt, J. (2001). The emotional dog and its rational tail: A social intuitionist approach to moral judgment. Psychological Review, 108, 814-834.

Hibbert, S., Smith, A., Davies, A. \& Ireland, F. (2007). Guilt appeals: Persuasion knowledge and charitable giving. Psychology and Marketing, 24, 723-742.

Holmes, J. G., Miller, D. T. \& Lerner, M. J. (2002). Committing altruism under the cloak of self-interest: The exchange fiction. Journal of Experimental Social Psychology, 38, 144-151.

Jonas, E., Schimel, J., Greenberg, J. \& Pyszczynski, T. (2002). The Scrooge effect: Evidence that mortality salience increases prosocial attitudes and behavior. Personality and Social Psychology Bulletin, 28, 1342 1353.

Kelley, J. (1989). Australians' Attitudes to Overseas Aid: Report from the National Social Science Survey. Canberra: Australian Government Publishing Service.

Knight, G. P., Johnson, L. G., Carlo, G. \& Eisenberg, N. (1994). A multiplicative model of the dispositional antecedents of a prosocial behavior: Predicting more of the people more of the time. Journal of Personality and Social Psychology, 66, 178183.

Kogut, T. \& Ritov, I. (2011). The identifiable victim effect: Causes and boundary conditions. In: D. M. Oppenheimer \& C. Olivola, eds. The Science of Giving: Experimental Approaches to the Study of Charity, pp. 133145. New York: Psychology Press.
Krebs, D. L. (1970). Altruism: An examination of the concept and a review of the literature. Psychological Bulletin, 73, 258-302.

Latane, B. \& Nida, S. (1981). Ten years of research on group size and helping. Psychological Bulletin, 89, 308-324.

Levine, M., Cassidy, C., Brazier, G. \& Reicher, S. (2002). Self-categorisation and bystander non-intervention: Two experimental studies. Journal of Applied Social Psychology, 32, 1452-1463.

Levine, M. \& Thompson, K. (2004). Identity, place, and bystander intervention: Social categories and helping after disasters and emergencies. Journal of Social Psychology, 144 (3), 229-246.

Levy, S. R., Freitas, A. L. \& Salovey, P. (2002). Construing action abstractly and blurring social distinctions: Implications for perceiving homogeneity among, but also empathising with and helping, others. Journal of Personality and Social Psychology, 83, 1224-1238.

Levy, S. R., West, T. L., Ramirez, L. \& Karafantis, D. M. (2006). The Protestant work ethic: A lay theory with dual intergroup implications. Group Processes and Intergroup Relations, 9, 95-115.

Moore, S. E. H. (2008). Ribbon Culture: Charity, Compassion and Public Awareness. Basingstoke: Palgrave Macmillan.

Penner, L. A., Dovidio, J. F. \& Piliavin, J. A. (2005). Prosocial behavior: Multilevel perspectives. Annual Review of Psychology, 56, 365-392.

Perrine, R. M. \& Heather, S. (2000). Effects of a picture and even-a-penny-will-help appeals on anonymous donations to charity. Psychological Reports, 86, 551-559.

Polonsky, M. J., Shelley, L. \& Voola, R. (2002). An examination of helping behavior - some evidence from Australia. Journal of Nonprofit \& Voluntary Sector Marketing, 10, 67-82.

Radley, A. \& Kennedy, M. (1995). Charitable giving by individuals: A study of attitudes and practice. Human Relations, 48, 685709.

Rushton, J. P. (1975). Generosity in children: Immediate and long-term effects of modelling, preaching, and moral judgment. Journal of Personality and Social Psychology, 31, 459-466.

Sargeant, A. \& Lee, S. (2004). Trust and relationship commitment in the United Kingdom voluntary sector: Determinants of donor behavior. Psychology \& Marketing, $21,613-635$ 
Saucier, D. A., Miller, C. T. \& Doucet, N. (2005). Differences in helping whites and blacks: A meta-analysis. Personality and Social Psychology Review, 9, 2-16.

Simmons, R. G. (1991). Altruism and sociology. Sociological Quarterly, 32, 1-22.

Simon, A. F. (1997). Television news and international earthquake relief. Journal of Communication, 47, 82-93.

Slovic, P. (2007). If I look at the mass I will never act: Psychic numbing and genocide. Judgement and Decision Making, 2, 79-95.

Staub, E. (1974). Helping a distressed person: Social, personality, and stimulus determinants. Advances in Experimental Social Psychology, 7, 293-341.

Strack, F., Schwarz, N. \& Kronenberger, A. (1987). Vorstellbarkeit, Empathie und Hilfeverhalten: Zur Umsetzung von Laborbefunden im Feld. Gruppendynamik, 18, 179-188.
Stroebe, W. \& Stroebe, M. (1996). The social psychology of social support. In: E. T. Higgins \& A. W. Kruglanski, eds. Social Psychology: Handbook of Basic Principles, pp. 597-621. New York: Guilford.

Thomas, E. F., McGarty, C. \& Mavor, K. I. (2009). Transforming 'apathy into movement': The role of prosocial emotions in motivating action for social change. Personality and Social Psychology Review, 13, 310-333.

UN's OCHA (2007). An organisation's financial tracking service. [Cited 25 May 2007.] Available from URL: http://ochaonline.un. org/

van Leeuwen, E. (2007). Restoring identity through outgroup helping: Beliefs about international aid in response to the December 2004 tsunami. European Journal of Social Psychology, 37, 661-671.

Warren, P. E. \& Walker, I. (1991). Empathy, effectiveness and donations to charity:
Social psychology's contribution. British Journal of Social Psychology, 30, 325337.

Wiesenthal, D. L., Austrom, D. \& Silverman, I. (1983). Diffusion of responsibility in charitable donations. Basic and Applied Social Psychology, 4, 17-27.

Wrathall, C. \& Ellis, M. (2006). Cradling the controlling interest. Financial Times, How to spend it Magazine October 2006, 910.

Wunderink, S. R. (2002). Individual financial donations to charities in The Netherlands: Why, how and how much? Journal of Nonprofit \& Voluntary Sector Marketing, 10, 21-39.

Zagefka, H., Noor, M., Brown, R., Randsley de Moura, G. \& Hopthrow, T. (2011). Donating to disaster victims: Responses to natural and humanly-caused events. European Journal of Social Psychology, 41, 353-363.

\section{Appendix I}

- Civil war in Colombia (Central America): Thousands of people have died during the long civil war in Colombia, and many more have fled to save their lives. These refugees now are in urgent need of outside support, or they will face starvation.

- Famine in West Africa (Africa): Farmers' crops in West Africa, more specifically in the countries of Niger, Mali, Burkina Faso and Mauritania, were devastated by poor rainfall this year. Thousands of people are starving or have already died, do not have enough food to survive, and are reliant on outside support.

- Earthquake in Pakistan, India, and Kashmir (Asia): The recent earthquake in Pakistan and neighbouring countries has caused thousands of deaths, and there are many people who have lost everything. They now depend on outside support to survive and rebuild their lives.

- Civil war in Sudan, particularly Darfur (Africa): The longlasting civil war in Sudan and more recently the conflict in
Sudan's province of Darfur has caused thousands of deaths, and innumerable refugees. These refugees now depend on outside support for their survival.

- Hurricane Stan victims in Guatemala and other Central American countries (Central America): Thousands of people have died and many more have lost everything following Hurricane Stan, which caused torrential rains and mudslides in Guatemala this year. There are many survivors who are in desperate need for outside support.

- Civil war in Nepal (Asia): For years, there has been a violent civil war raging in Nepal - civilians are often victims. Thousands of people have been killed, and there are many refugees that are in desperate situations and need outside support.

- Hurricane Katrina in the USA (North America): Thousands of people have been killed and made homeless by Hurricane Katrina, which hit New Orleans and other places on the Gulf Coast this year. Many of the worst affected belong to the poorest segments of society, and are in need of support to rebuild their lives. 